\title{
Building Relationships Between Business Schools And Students: An Empirical Investigation Into Student Retention
}

Phani Tej Adidam, (Email: padidam@mail.unomaha.edu), University of Nebraska at Omaha R. Prasad Bingi, (Email: bingi@ipfw.edu), Indiana-Purdue University

Birud Sindhav, (Email: bsindhav@mail.unomaha.edu), University of Nebraska at Omaha

\begin{abstract}
This study uses the relationship marketing theory of commitment and trust as a framework to investigate the issue of student retention in business schools. Structural equation modeling was used to examine relationships specified by Morgan and Hunt's (1994) theory of relationship marketing. Students' commitment to the business schools were determined by perceived benefits of attending the school, perceived similarity of values between the school and the students, and trust between the professors and the students. Commitment increased intentions to remain at the business school.
\end{abstract}

\section{Introduction}

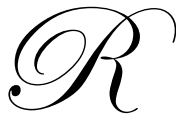

etention of business school students is emerging as a critical issue. The concern among business school deans and administrators over why students drop out has increased due to declining enrollments. This decline has been attributed to, among various factors, a booming economy and intense competition among schools to attract a declining number of students (Tom, 1999). In order to offset this attrition, and maintain stable enrollments, many business schools are mounting aggressive student recruiting efforts (Dixon, 1995). However, there is growing recognition that student retention efforts are also equally important (Hossler, 1991). As evidenced in the customer satisfaction literature, many business school deans are learning from their corporate counterparts that it is less costly to retain an existing customer than to gain a new one (Scott, 2000; Walls and Zahay, 2000). Hence several business school administrators have made it a high priority to focus on retention by developing strong relationships with students (Tom, 1999).

This study examines issues that could provide guidance to business school deans and administrators in developing strong relationships with students. Specifically, the central objective of this study is to explore the effects of key variables on student retention. In other words, how can we reduce a student's likelihood of leaving a business school? We draw upon the commitment-trust theory of relationship marketing to investigate this question.

First, we present a very brief literature review on student retention. Second, we explicate the commitment-trust theory of relationship marketing (Morgan and Hunt, 1994). Third, we test this model from data collected at three midwestern universities. Finally, we arrive at certain guidelines that would allow business school administrators to develop stronger relationships with students, and thereby enhance retention.

\section{Literature Review}

\section{Student Retention}

There are several studies that have examined the antecedents of student retention (cf. McLaughlin, Brozovsky, and McLaughlin, 1998). One of the most pivotal themes in this research is the idea that a student's involvement in the 
social environment as well as the academic environment is critical to success in college (Pace, 1979). The quality of student effort is the major determinant in the amount of student learning and retention. Indeed, the more a student learns, the higher the likelihood of returning back the next semester. The sense of student's social involvement is increased or decreased through quality of interactions with both the faculty and staff (Tinto, 1993). Research has shown that institutional culture has both direct and indirect effects on the student's propensity to become involved in both academic and non academic activities (Braxton, Vesper, and Hossler, 1995). Clagget (1992), Ewell (1987, 1993, 1995), and Pascarella and Terenzini (1991) have exhaustive reviews of the aforementioned issues related to student retention.

Although the educational literature has examined associations between institutional culture, student involvement, and retention, it has ignored other variables of interest to educators. The development of strong relationships between students and business schools has not been studied as a possible indicator of high retention (Holdford and Wright, 1997). More specifically, the roles of commitment and trust, as well as several of their antecedents and consequences, have been absent from consideration. There is a relationship marketing framework emerging in the strategic marketing discipline that can help offset this deficiency, and thereby enhance and complement the literature base. We shall now examine the relationship marketing model.

\section{Commitment-Trust Theory of Relationship Marketing}

The Commitment-Trust Theory of Relationship Marketing model (C-T model) proposes that relationship commitment and trust are key variables for successful relationships because they promote cooperative behaviors between relationship partners and encourage them to maintain long-term relationships (Morgan and Hunt, 1994). They suggest that relationships characterized by trust and commitment allow partners to be more accepting of high-risk situations because each party believes that the other party will not be inclined to act opportunistically, rather they would engage in activities that are in the long-term best interests of both partners. The C-T Model proposes that commitment and trust are key mediating variables between five important antecedents (i.e., relationship benefits, shared values, communication, relationship termination costs, and opportunistic behavior) and four outcomes (i.e., cooperation, functional conflict, uncertainty reduction, and propensity to leave). In other words, as expressed in Figure 1, the C-T model allows us to investigate not only the direct and indirect effects of commitment and trust, but also their antecedents' effects on a partner's propensity to leave the relationship, which is our focus of interest. Holdford and Wright (1997) used the C-T Model to investigate the relationships between pharmacy schools and students.

Commitment. Morgan and Hunt (1994, p.23) defined relationship commitment as "an exchange partner believing than an ongoing relationship with another is so important as to warrant maximum efforts at maintaining it."Similarly, Moorman, Zaltman and Deshpande (1992, p. 316) defined relationship commitment as "an enduring desire to maintain a valued relationship." Commitment is enhanced when exchange partners share similar values, and that these partners perceive that the relationship has exceptional benefits and high termination costs. We briefly discuss these concepts now.

Relationship benefits refer to the quality of services and goods relative to other options. Business students might be willing to continue their relationship with a school that offers them a mix of superior benefits such as location, cost of tuition, internship opportunities, better placements, and educational quality than another school.

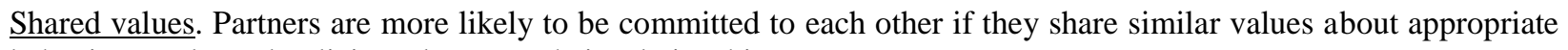
behavior, goals, and policies relevant to their relationship.

Termination costs are described as the perception of net losses (either financial, emotional, or time) that may result from the dissolution of a relationship. These losses cannot be replaced by relationships with alternative partners. The perceived costs to a student of terminating a relationship with business school might be the loss of friendships developed at school or the risk that course credits at the school might not be accepted at another school (Holdford and Wright, 1997).

Trust. Trust is defined as the "confidence in an exchange partner's reliability and integrity" (Morgan and Hunt, 1994, p. 23). Further, trust is enhanced when partners share similar values, and when partners communicate. On the hand, trust is decreased when partners are perceived to engage in opportunistic behavior. We briefly discuss these concepts now. 
Insert Figure 1 about here 
Shared values are common antecedents to both trust and commitment. Perceptions of shared values between partners increase the perceived ability of partners to predicts the other's motives and behavior and, therefore, increase trust. As Holdford and Wright (1997) explain, when professors and students share similar values such as a strong work ethic, students may be more likely to attribute the professor's motives for giving tough assignments or challenging exams to the work ethic rather than less desirable attributions, such as a mean spirit on the part of the professor.

Communication is the sharing of meaningful and timely information between partners. In a business school, communication may happen regarding curricular (course-related) as well as extra-curricular (internships, clubs, professional meetings, etc.) issues. Professors who communicate with students about what to expect in a course and on exams might enhance student trust. Additionally, communication between professors and students can prevent misunderstandings and allow the resolution of conflicts.

Opportunistic behavior is a violation of implicit or explicit role behaviors. Professors perceived by students as acting in their own best interests might lose student trust. For example, students who perceive professors as unprepared for class because of excessive involvement in consulting or research might consider those professors to more opportunistic and therefore, less trustworthy (Holdford and Wright, 1997).

Outcomes of Trust. According to the C-T Model, there are three direct outcomes of trust - cooperation, uncertainty reduction, and functional conflict. Trust also affects a partner's propensity to leave in an indirect manner. We briefly discuss these concepts now.

Cooperation results in outcomes that exceed what would be achieved in a relationship in which partners do not work together (Morgan and Hunt, 1994). When cooperation prevails, the partners work toward a common goal. In the case of a business school, students who are involved in the academic setting with their faculty members and administrators can maximize their educational experiences. According to Holdford and Wright (1997), a student's level of cooperation may be partial result of his or her trust in the capabilities and motives of the professors and the school. Cooperation is also an outcome of commitment. The more committed the partners are to each other, the more they will cooperate toward the achievement of their mutually beneficial objectives. In our scenario, the more committed the school is toward the student, the higher the likelihood of the student cooperating toward their mutually beneficial objective-graduation.

Functional conflict is a constructive manner of criticizing your partner. The outcome of functional conflict is likely to be positive, and of mutual benefit. Relationships get strengthened because of such conflicts. Functional conflict leads to an opportunity to communicate and readjust expectations. An example of one of the most common functional conflict situations between students and professors: Students may become upset at the perceived rigidity of the professor in insisting on randomly designing teams for a class project, rather than allowing the students to design their own teams. The professor may explain the nature of the class project, and the reason why it is appropriate to randomly assign students to teams. In this scenario, conflict can be functional because the professor gains an understanding of the students' concerns, and the students learn the value of working with different kind of people. Trust encourages partners to treat conflicts as functional and find win-win solutions.

Decision-making uncertainty is the extent to which partners perceive they have sufficient information to make decisions with confidence. Those students who trust the professors and school administrators may be less inclined to second-guess their decisions of school or professional choice.

Trust permits partners to take a long-term perspective of relationships. The relationship reduces suspicion that partners will take advantage of each other for short-term gains because of the risk to the relationship. This long-term relationship leads to enhanced commitment. Hence, trust has a direct effect on commitment.

Outcomes of Commitment. According to the C-T Model, there are two outcomes of commitment-cooperation and propensity to leave. Propensity to leave, our focal construct, is a partner's intention to terminate the relationship in the near future. Due to a low level of commitment, a student may decide to prematurely terminate his/her relationship with the school. In other words, there is a negative relationship between relationship commitment and propensity to leave. 
Hypotheses. Stated in formal fashion, our study tests 12 hypotheses:

$\mathbf{H}_{1}$ : There is a positive relationship between termination costs and relationship commitment.

$\mathbf{H}_{2}$ : There is a positive relationship between relationship benefits and relationship commitment.

$\mathbf{H}_{3}$ : There is a positive relationship between shared values and relationship commitment.

$\mathbf{H}_{4}$ : There is a positive relationship between trust and relationship commitment.

$\mathbf{H}_{5}$ : There is a positive relationship between shared values and trust.

$\mathbf{H}_{6}$ : There is a positive relationship between communication and trust.

$\mathbf{H}_{7}$ : There is a negative relationship between opportunistic behavior and trust.

$\mathbf{H}_{8}$ : There is a negative relationship between relationship commitment and propensity to leave.

$\mathbf{H}_{9}$ : There is a positive relationship between relationship commitment and cooperation.

$\mathbf{H}_{\mathbf{1 0}}$ : There is a positive relationship between trust and cooperation.

$\mathbf{H}_{11}$ : There is a positive relationship between trust and functional conflict.

$\mathbf{H}_{12}$ : There is a positive relationship between trust and uncertainty reduction.

Summary. We have attempted to apply Morgan and Hunt's (1994) C-T Model to explaining the relationships between business schools and students. How can business school administrators and professors enhance student retention? Student retention can be enhanced by developing long-term and strong relationships with the students. Trust and commitment are the key constructs responsible for developing long-term relationships. In other words, high levels of trust and commitment between business schools and students increase cooperation between business schools and students, and decrease students' propensity to leave.

\section{Research Method}

Research Setting

As a research setting, we used a sample of undergraduate students at three mid-western business schools. The study began with in-depth interviews with seven undergraduate students at a mid-western university. From these interviews (and the literature review discussed previously), a draft questionnaire was pretested with the same seven undergraduate students. Respondents were encouraged to identify unclear items and suggest changes. After making the suggested changes, the questionnaire was personally reviewed by three faculty members who possessed substantial survey research experience. This review revealed no major problems with any of the measures or response formats. In the questionnaire, each student was asked to rate the extent to which they agreed or disagreed with the items on a 5 point likert-type of scale (Strongly Agree/Strongly Disagree). All of the eleven measures are of reflective type. A sample of the measures is provided in Appendix A. Further information regarding the student's class level, gender, age, and whether either parent has a college degree, was collected in order to provide a descriptive analysis of the sample. Constructs used in this research are measured using self-report measures of the respondents' perceptions. Support for the use of self-report measures is found in Walker, Churchill, and Ford (1977).

\section{Research Sample}

The questionnaire was administered to 331 undergraduate business students in three mid-western universities. A total of 307 students $(92 \%)$ completed the survey, of which $46 \%$ of the students had at least one parent who has a college degree. The majority of the students (40\%) were sophomores, and 33\% were juniors. 59\% of the respondents were women, and 55\% of the students were between 18-21 years of age. Complete sample description is provided in Table 1.

Analysis

MANOVA analysis revealed no differences in commitment or trust by class level, age, gender, or parents' educational background. LISREL 8 (Jöreskog and Sörbom, 1993) was used to facilitate the confirmatory factor analyses of the eleven measures (Commitment, Trust, Relationship benefits, Termination costs, Shared values, Communication, Opportunistic behavior, Cooperation, Functional conflict, Uncertainty reduction, and Propensity to leave) used in this study. Using the two-step approach, the measures are analyzed simultaneously, but separately from the structural model, 
to determine the quality of the measures in terms of the traditional concerns for scientific measures; that is, their validity and reliability (Anderson and Gerbing, 1988). The covariance matrix served as the input for the analysis.

The measurement model included 39 items across eleven reflective constructs. The resulting model yielded an acceptable fit $\left[\chi_{(109)}^{2}=347.8(\mathrm{p}=0.0001)\right.$, goodness-of-fit index $(\mathrm{GFI})=0.93$, comparative fit index $(\mathrm{CFI})=0.95$, normed fit index $(\mathrm{NFI})=0.96$, non-normed fit index $(\mathrm{NNFI})=0.96$, root mean square error of approximation $(\mathrm{RMSEA})=0.052$, and root mean square residual $(\mathrm{RMR})=0.041]$. Further, all item loadings on the respective constructs were statistically significant at $\mathrm{t}>1.65$ (Anderson, 1987). The reliability for the composite of the measures, and the average variance extracted are listed in Table 2. Tests for unidimensionality and discriminant validity for each construct were also performed. Based on these outcomes, analysis of the structural model was performed.

Results

The structural model presented in Figure 2 was tested using maximum-likelihood LISREL 8. The structural model has a resulting GFI of $0.89, \mathrm{CFI}=0.91, \mathrm{NFI}=0.94, \mathrm{NNFI}=0.96, \mathrm{RMR}=0.042, \mathrm{RMSEA}=0.051$, and $\chi_{(139)}^{2}=$ $383.40(\mathrm{p}=0.000)$. Assessing the results in terms of the paths, all the twelve proposed paths have the correct direction of signs and significant $t$-values. In other words, all the twelve hypotheses have been empirically corroborated. In the structural model, commitment has a direct relationship with propensity to leave, while trust, relationship benefits, shared values, termination costs, communication, and opportunistic behavior have indirect relationships with propensity to leave. Therefore, in order to compare and contrast the effects of these two key variables and their antecedents on a student's propensity to leave, we need to investigate their standardized total effects (Table 3). Not surprisingly, commitment has the maximum total effect on a student's propensity to leave, and accounted for $46 \%$ of the variance in propensity to leave.

\section{Implications And Future Research Directions}

\section{Discussion}

We found overwhelming support for the C-T Model of Relationship Marketing in studying the issue of student retention in business schools. Commitment has the maximum effect on a student's propensity to leave. In other words, high levels of relationship commitment resulted in a decreased desire for students to leave the business school. Commitment also has a positive and substantive effect on cooperation between students and professors. This enhances the desire on the part of the student to continue in the business school till successful graduation. We can increase our commitment level by enhancing our level of trust with the students. Intuitively it makes sense that the more we trust each other, the more we will be committed toward one another.

Increased levels of trust between the business school and students also succeeded in enhanced cooperative behavior. Trust had two other positive effects. First, it had a positive impact on reducing cognitive dissonance in students' minds, as their decision-making uncertainty considerably decreased. The more the business school increases the mutual trust, the more comfortable the students will feel to be a part of the business school. This greatly reduces any considerations of whether they made the wrong decisions in joining this business school. Second, enhanced levels of trust between professors/staff and students increased their levels of candor. When conflict situations arise, there is a confidence that the same will be resolved in a mutually beneficial manner. Once again, this leads to a comfortable feeling within the mind of the student.

Given that commitment and trust are important constructs affecting student retention in business schools, how can we enhance commitment and trust? As mentioned above, the most important approach to increasing commitment is to increase mutual trust between business schools and students. The more they trust each other, the more they will be committed toward one another. How else can we increase commitment? Our study corroborated that commitment to business schools was determined by three antecedents. These are, in order of importance, perceived benefits of the relationship, perceived similarity of values, and high levels of termination costs. First, we can increase commitment by promoting the perceived benefits of the relationship to the students. Students will continue their relationship with a business school that offers them a mix of superior benefits such as location, cost of tuition, internship opportunities, 
Table 1: Sample Description

\begin{tabular}{llc}
\hline Variable & Class $(\mathbf{N}=\mathbf{3 0 7})$ & $\mathbf{N}$ (percent) \\
Level & Senior & $82(27)$ \\
& Junior & $103(33)$ \\
& Sophomore & $122(40)$ \\
Gender & Male & $126(41)$ \\
& Female & $181(59)$ \\
Age & $18-19$ & $52(17)$ \\
& $20-21$ & $117(38)$ \\
& $22-24$ & $64(21)$ \\
& $25-26$ & $40(13)$ \\
& $27-29$ & $21(7)$ \\
Either parent has a & & $140(46)$ \\
college degree? & Yes & $167(54)$ \\
\hline
\end{tabular}

Table 2: Descriptive Information and Reliability of the Reflective Measures

\begin{tabular}{lccccr}
\hline Construct & Mean & S.D. & $\begin{array}{c}\text { Composite } \\
\text { Reliability }\end{array}$ & $\begin{array}{c}\text { Average } \\
\text { Variance } \\
\text { Extracted }\end{array}$ & $\begin{array}{r}\text { No. of } \\
\text { Items }\end{array}$ \\
Termination Costs & 3.66 & 0.51 & 0.70 & 0.83 & 2 \\
Relationship benefits & 3.86 & 0.44 & 0.76 & 0.73 & 5 \\
Shared Values & 3.41 & 0.77 & 0.80 & 0.72 & 4 \\
Communication Quality & 3.81 & 0.69 & 0.73 & 0.56 & 3 \\
Opportunistic Behavior & 1.90 & 0.66 & 0.71 & 0.61 & 3 \\
Relationship Commitment & 3.48 & 0.79 & 0.86 & 0.69 & 3 \\
Trust & 3.65 & 0.81 & 0.81 & 0.63 & 4 \\
Propensity to Leave & 1.76 & 0.86 & 0.79 & 0.69 & 4 \\
Cooperation & 3.33 & 0.65 & 0.61 & 0.76 & 4 \\
Functional Conflict & 2.95 & 0.87 & 0.65 & 0.77 & 3 \\
Uncertainty Reduction & 3.06 & 0.97 & 0.74 & 0.78 & 3 \\
\hline
\end{tabular}

Table 3: Total Standardized Effects on Propensity to Leave

\begin{tabular}{lc}
\hline Path & Estimate \\
Commitment $\rightarrow$ Propensity to Leave & $\mathbf{- 0 . 6 6 8}$ \\
Trust $\rightarrow$ Propensity to Leave & -0.483 \\
Shared Values $\rightarrow$ Propensity to Leave & -0.417 \\
Relationship Benefits $\rightarrow$ Propensity to Leave & -0.351 \\
Communication $\rightarrow$ Propensity to Leave & -0.246 \\
Termination Costs $\rightarrow$ Propensity to Leave & -0.218 \\
Opportunistic Behavior $\rightarrow$ Propensity to Leave & 0.092 \\
\hline
\end{tabular}


Insert Figure 2 about here 
better placements, networking options, and educational quality. Business school administrators must promote these perceived relationship benefits on a continuous basis, rather than during initial recruitment of students. Students must constantly be made aware of the benefits of being associated with the business school. Second, business schools can increase commitment by demonstrating a perceived similarity of values with their students. The more the professors/staff and students have similar ideas and positions on important issues such as work-load, learning behavior, and assessments, the more committed they will be to the relationship. Third, the more the students discern the high costs of terminating the relationship, the higher will be their commitment. Rather than moving elsewhere, they will remain committed to the relationship.

Our study found three antecedents that increased trust in the relationship. These are, in order of importance, quality of communication, perceived similarity of values, and student perceptions that professors will not act opportunistically. First, it has been well established in the literature that the better the quality of communication, the greater the level of trust among partners. Business school administrators and faculty should maintain formal and informal levels of contact with their students. Transparency in communicating important and relevant issues with the students removes unnecessary suspicion, and thereby vastly enhances trust. Second, as mentioned above, business schools can increase trust by demonstrating a perceived similarity of values with their students. Third, a relationship is strengthened if both the parties know that the other will not act in a self-serving and opportunistic manner. Business schools must therefore discourage professors from acting opportunistically with the students. The less opportunistic the behavior, the more trustworthy the relationship.

\section{Implications for Student Retention}

There are six important implications of this study. First, enhancing student commitment to the business school should be given top priority. Second, encourage professors and staff to proactively develop trusting relationships with students. Third, promote the positive relationship benefits to the students on a continuous basis. Fourth, develop and maintain formal and informal channels of communication with students. Fifth, develop and focus on shared values between the business school and students. Finally, discourage opportunistic behavior on the part of professors and/or staff.

\section{Future Research Directions}

Future studies should also develop the "propensity to leave" construct further. In other words, a student could leave the business school and transfer to another business school. Or, a student might transfer to another non-business school within the same university. A student might quit education altogether, or might have an intention to return at some future point in time. As we can see, there will be different implications for these different outcomes. Future studies must incorporate these different outcomes and get a deeper understanding of student attrition.

Since we adopted the relationship marketing framework, there could be other outcomes developing strong and long-term relationships. Student retention is merely one outcome. We could study other, and perhaps more consequential, outcomes of developing relationships with students. What is the level of their willingness to recommend this program to others? What is the level of their willingness to support this business school as an alumnus? It would be interesting to study all these outcomes in a single model.

Also, we believe that the model is not limited just to business schools, but could be applied to other schools and universities as well. This type of generalization requires that the model be thoroughly tested in varieties of situations using varieties of research methods. In this research we have attempted to test the C-T Model in a business school setting using survey research methodology. Future research would include testing the model in different settings using different research methodologies.

\section{Conclusion}

Through this study, we have attempted to alleviate the deficiency in the literature on student retention. While extant literature focuses on roles of institutional culture, school environment, and student participation, this study adds 
value by focusing on the role of relationship building between business schools and their students. The C-T Model of Relationship Marketing has been successfully applied to study the issue of student retention in business schools. Business school deans, administrators, and professors must develop strong and long-term relationships with their students, so that their propensity to leave depreciates.

\section{References}

1. Anderson, J. C., \& Gerbing, D. W. (1988). Structural modeling in practice: A review and recommended twostep approach. Psychological Bulletin, 103 (3), 411-423.

2. Braxton, J. M., Vesper, N., \& Hossler, D. (1995). Expectations for college and student persistence. Research in Higher Education, 36 (5), 595-612.

3. Clagget, C. (1992). Enrollment management. In M. A. Whitney, J. D. Porter, and R. H. Fenske (eds.), The Primer for Institutional Research. Resources for Institutional Research 7, pp. 12-24. Tallahassee: Association for Institutional Research.

4. Dixon, R. R. (1995). Making enrollment management work. New Directions for Student Services 71.

5. Ewell, P. T. (1987). Principles of longitudinal enrollment analysis: Conducting retention and student flow studies. In G. W. McLaughlin and J. A. Muffo (eds.), A Primer on Institutional Research, pp. 1-19. Tallahassee: Association for Institutional Research.

6. Ewell, P. T. (1993). Retention and enrollment management. In W. R. Fendley, Jr., and L. T. Seeloff (eds.), Reference Sources: An Annotated Bibliography, pp. 85-91. Tallahassee: Association for Institutional Research.

7. Ewell, P. T. (ed.) (1995). Student tracking: New techniques, new demands. New Directions for Institutional Research 87.

8. Holdford, D. A., \& Wright, S. S. (1997). Testing trust-commitment theory in relationships between pharmacy schools and students. American Journal of Pharmaceutical Education, 66, 249-56.

9. Hossler, D. (ed.) (1991). Evaluating student recruitment and retention programs. New Directions for Institutional Research 70.

10. Jöreskog, K. G., \& Sörbom, D. (1993). LISREL 8. Chicago: Scientific Software Inc.

11. McLaughlin, G. W., Brozovsky, P. V., \& McLaughlin, J. S. (1998). Changing perspectives on student retention: A role for institutional research. Research in Higher Education, 39 (1), 1-17.

12. Moorman, C., Zaltman, G., \& Deshpande, R. (1992). Relationships between providers and users of marketing research: The dynamics of trust within and between organizations. Journal of Marketing Research, 29 (3), 31429.

13. Morgan, R. E. \& Hunt, S. D. (1994). The commitment-trust theory of relationship marketing. Journal of Marketing, 58 (3), 20-38.

14. Pace, C. R. (1979). Measuring Outcomes of College: Fifty Years of Findings and Recommendations for the Future. San Francisco: Jossey-Bass.

15. Pascarella, E., \& Terenzini, P. (1991). How College Affects Students. San Francisco: Jossey-Bass.

16. Scott, D. (2000). Customer Satisfaction: Important Tools for Building Important Relationships. Menlo Park, CA: Crisp Publications.

17. Tinto, V. (1993). Leaving College: Rethinking the Causes and Cures of Student Attrition, $2^{\text {nd }}$ ed. Chicago: University of Chicago Press.

18. Tom, Gail (1999). A post-mortem study of student attrition at the college of business administration. Journal of College Student Retention, 1 (3), 267-87.

19. Walker, Jr., O. C., Churchill, Jr., G. A., \& Ford, N. M. (1977). Motivation and performance in industrial selling: Present knowledge and needed research. Journal of Marketing Research, 14, 156-168.

20. Walls, S., \& Zahay, D. L. (2000). Managing Customer Relationships. Cambridge, MA: Marketing Science Institute. 


\section{Appendix A: Sample Measures Used in the Study}

$\begin{array}{lll}\text { Termination Costs } & - & \text { Leaving this business school for another would be relatively easy for me. } \\ \text { Relationship Benefits } & - & \text { The costs of leaving this business school are very minimal for me. } \\ \text { Shared Values } & - & \text { The location of this business school makes this the ideal school to attend } \\ \text { This business school provides several beneficial opportunities such as internships } \\ \text { for its students } \\ \text { The faculty/staff and I have similar positions regarding appropriate behavior in the } \\ \text { classroom. }\end{array}$


Notes 